Subscriber access provided by SDIS @ INRS | http://sdis.inrs.ca

\title{
Article
}

\section{Evaluating benthic recovery decades after a major oil spill in the Laurentian Great Lakes}

\author{
Karine Bertrand, and Landis Hare
}

Environ. Sci. Technol., Just Accepted Manuscript • DOI: 10.1021/acs.est.7b02392 • Publication Date (Web): 27 Jul 2017

Downloaded from http://pubs.acs.org on August 1, 2017

\section{Just Accepted}

"Just Accepted" manuscripts have been peer-reviewed and accepted for publication. They are posted online prior to technical editing, formatting for publication and author proofing. The American Chemical Society provides "Just Accepted" as a free service to the research community to expedite the dissemination of scientific material as soon as possible after acceptance. "Just Accepted" manuscripts appear in full in PDF format accompanied by an HTML abstract. "Just Accepted" manuscripts have been fully peer reviewed, but should not be considered the official version of record. They are accessible to all readers and citable by the Digital Object Identifier (DOI®). "Just Accepted" is an optional service offered to authors. Therefore, the "Just Accepted" Web site may not include all articles that will be published in the journal. After a manuscript is technically edited and formatted, it will be removed from the "Just Accepted" Web site and published as an ASAP article. Note that technical editing may introduce minor changes to the manuscript text and/or graphics which could affect content, and all legal disclaimers and ethical guidelines that apply to the journal pertain. ACS cannot be held responsible for errors or consequences arising from the use of information contained in these "Just Accepted" manuscripts. 


\section{Evaluating benthic recovery decades after a major oil spill in the Laurentian Great Lakes}

Karine Bertrand and Landis Hare ${ }^{*}$

Institut national de la recherche scientifique, Eau Terre Environnement (INRS-ETE), Université du Québec, 490 de la Couronne, Quebec City, Québec, G1K 9A9, Canada

Word count: 4,400 words $+2,400$ words ( 2 figures at $600+4$ figures at 300 ) $=6,800$ words.

Keywords: Petroleum, Oil spill, Benthos, Great Lakes, Chironomus, Deformities

*Corresponding author: landis@ete.inrs.ca, telephone 418-654-2640, fax 418-654-2600 
1 ABSTRACT: The long-term effects of oil spills on freshwater organisms have been little

2 studied. In 1950, a large oil spill (10 million L) covered the harbor area of Parry Sound, Ontario,

3 the deepest port in the Laurentian Great Lakes. Ecological impacts were not studied at the time,

4 but 25 years later three-quarters of the Chironomus cucini larvae (Insecta, Diptera,

5 Chironomidae) living in the harbor area were reported to be deformed. We returned six decades

6 after the spill and found that the frequency of deformities had returned to background levels, and

7 that the community of burrowing invertebrates has largely recovered. By dating sediment cores

8 and measuring the depth distribution of oils, we conclude that, although the oil persists six

9 decades after the spill, sufficient uncontaminated sediment has covered the oil thereby putting it

10 out of reach of most burrowing animals. Provided that the sediment remains undisturbed, the

11 buried oil is unlikely to exert further negative effects on the biota in spite of the fact that it will

12 likely persist for centuries.

13 TOC (Figure 3 of manuscript):

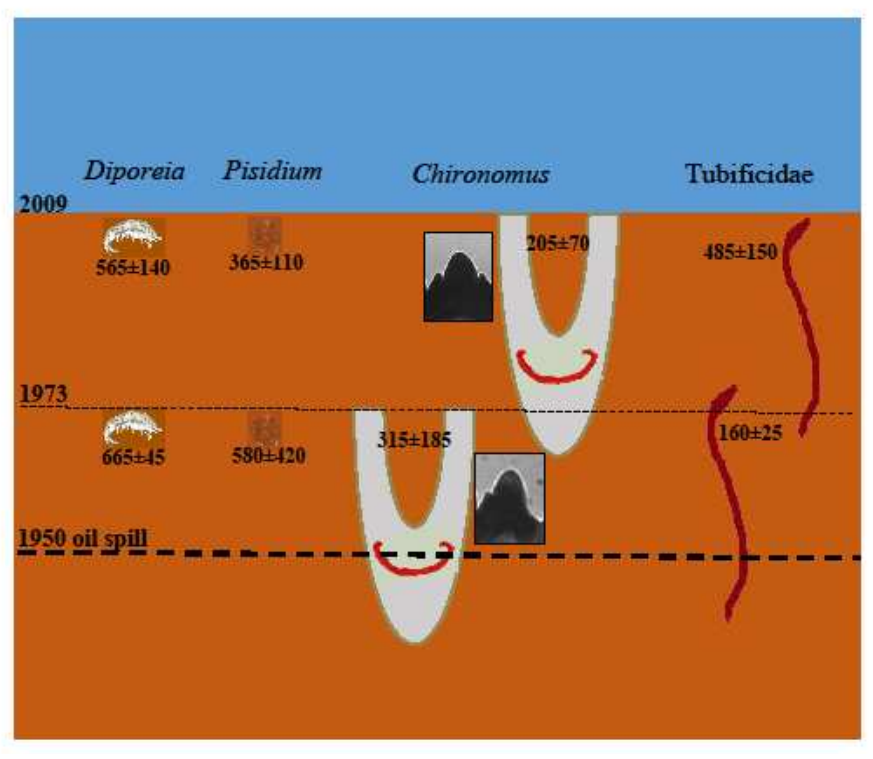




\section{Introduction}

16 Large oil spills in marine systems have made names such as Amoco Cadiz (France 1978), Exxon

17 Valdez (Alaska 1989), and Deepwater Horizon (Gulf of Mexico 2010) infamous, and the effects

18 of such spills have been extensively documented. ${ }^{1}$ Oil spills in fresh waters, while not of this

19 scale, can have major impacts in the short term, ${ }^{2}$ whereas their long-term impacts and the

20 persistence of oil in freshwater ecosystems are unknown. There is an urgent need for such

21 information given the increasing rate at which oil sands and other terrestrial sources of oil are

22 being exploited and their products transported over great distances by pipelines, trains and ships.

23 In 1950, one of the largest oil spills in the history of the Laurentian Great Lakes occurred in

24 Parry Sound, Ontario, Canada, when the rupture of an oil storage tank spilled 10 million L of

25 heavy bunker oil into Parry Sound Harbor. ${ }^{3}$ To put this spill in perspective, a very large oil spill

26 into the Kalamazoo River, Michigan, involved less than half this amount ( $\approx 4$ million L; Detroit

27 Free Press, 23 July 2011). Response measures after the 1950 Parry Sound spill were limited to a

28 few booms, ineffective attempts to burn-off the oil, and the use of sand to sink the oil to the lake

29 bottom. $^{3}$ Two and a half decades after the spill, sediment collected in the profundal zone of Parry

30 Sound Harbor contained substantial quantities of oil. ${ }^{4}$ Furthermore, three-quarters of the

31 Chironomus cucini (Webb 1969) larvae (Insecta, Diptera, Chironomidae) collected from these

32 sediments had deformed mouthparts. ${ }^{4}$ The results of many studies have evoked contaminants

33 such as oil as the cause of high proportions of deformities in field populations of Chironomus

34 larvae $e^{4,5,6,7}$ and this supposition is supported by the results of laboratory experiments. ${ }^{8,9,10}$

35 Six decades after the 1950 oil spill, we revisited Parry Sound where we collected large

36 numbers of Chironomus cucini larvae to determine if the frequency of larval deformities had

37 declined in the intervening decades. We also collected other invertebrates to determine if benthic 
community composition had changed since it was measured in the 1970s. Lastly, we collected

39

40

41

42

43

44

45

cores that allowed us to determine the depth of sediment that has been deposited since the oil spill, as well as to measure the vertical distribution of oil in the sediments and describe the history of the chironomid populations at the contaminated site. Overall, these measurements should allow us to relate the depth-distribution of oil in the sediment to the history and present state of benthic invertebrate populations in the impacted area. Given the lack of long-term studies on the impact of oil spills on freshwater biota, our data should be useful for estimating response times for benthic recovery in comparable systems.

\section{MATERIALS AND METHODS}

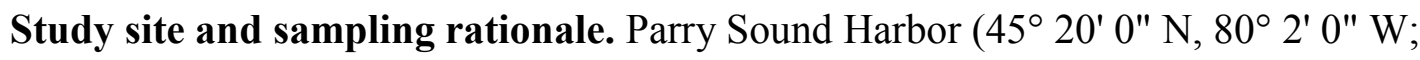
surface area $\left.\sim 3 \mathrm{~km}^{2}\right)$ is located at the eastern extremity of Parry Sound, a large bay $\left(50 \mathrm{~km}^{2}\right)$ on the eastern shore of Georgian Bay, Lake Huron. Beginning in the $19^{\text {th }}$ century, this major port received contaminants from activities such as shipping, forestry, and sewage from the town of

Parry Sound. ${ }^{3,4}$ In 1950, the rupture of a shore-side storage tank released $\sim 10$ million L of heavy bunker oil that covered much of the harbor and spread to the Sound itself. ${ }^{3}$ Two and a half decades later (1973), three-quarters of the Chironomus cucini larvae collected from harbor sediments were deformed. ${ }^{4}$

To determine if insects were still deformed 6 decades after the oil spill, we collected $C$. cucini larvae in 2006 and 2009 from the station (station 1; 22-m depth) originally sampled by Hare and Carter $^{4}$ (station 8; see map in Hare and Carter $^{4}$ ). In 2009, we also collected C. cucini at an additional station situated $\sim 0.7 \mathrm{~km}$ to the east (station $2 ; 24-\mathrm{m}$ depth) as well as sediment cores and grab samples for the determination of benthic community structure and the 
measurement of contaminants. Historical and current values are compared to those for a

61 reference station in Parry Sound (14-m depth; sampled in 2009) that is located beyond the reach

62 of the oil spill (station 34 in Hare and Carter ${ }^{4}$ ). All stations sampled are in the profundal zone,

63 and larvae of C. cucini are reported to be limited to this zone in Parry Sound. ${ }^{4}$ Chironomus

64 cucini are recognizable as members of the salinarius group of Chironomus species by the fact

65 that larvae lack ventral and lateral tubules on their abdomen. ${ }^{11}$ Chironomus cucini was reported

66 to be the only salinarius-group Chironomus species present in the hypolimnion of Parry Sound

67 Harbor, ${ }^{4}$ and this identification has since been confirmed using a combination of morphological,

68 cytological and genetic techniques. ${ }^{12}$

Sediment cores. We collected two sediment cores (A and B; length $50 \mathrm{~cm}$ ) at station 1

70 using a gravity corer. To avoid sediment displacement during transport, the ends of the core

71 samples were plugged using floral foam. In the laboratory, the polyvinyl-chloride core tubes

72 (6.7-cm diameter) were cut lengthwise into halves using a miniature circular saw and a wire was

73 used to separate the sediment lengthwise into two halves. For ${ }^{210} \mathrm{~Pb}$ dating and ${ }^{137} \mathrm{Cs}$

74 measurements, half of core A was cut into $0.5-\mathrm{cm}$ lengths for the first $10 \mathrm{~cm}$ and then into $1 \mathrm{~cm}$

75 lengths for the remainder of the core. These fresh samples were weighed, freeze dried, weighed

76 again and ground to a powder of which a minimum of $1 \mathrm{~g}$ was placed into a pre-weighed vial and

77 counted for $24 \mathrm{~h}$ in an ultra-low-background, high-purity, germanium, gamma spectrophotometer

78 (ORTEC). Counts were treated and data interpreted according to Appleby ${ }^{13}$ and Couture et al. ${ }^{14}$

79 Total lead $(\mathrm{Pb})$ measurements were obtained using an ITRAX X-ray fluorescence scanner

80 (Cox Analytical Systems). Measurements were made at intervals of $100 \mu \mathrm{m}$ and the resulting

81 data were treated using ImageJ (http://rsbweb.nih.gov/ij/). 
Total greases and oils were measured in subsamples collected at $0.5-\mathrm{cm}$ intervals along one

83 of the longitudinal halves of core B. To glass vials we added $4 \mathrm{~g}$ of homogenized sediment, $0.8 \mathrm{~g}$

84 of anhydrous magnesium sulfate $\left(\mathrm{MgSO}_{4}\right)$, and $16 \mathrm{~mL}$ of hexane. Vials were held in an

85 ultrasonic bath for $10 \mathrm{~min}$, shaken for $10 \mathrm{~min}$, and set aside to allow the $\mathrm{MgSO}_{4}$ to precipitate.

86 The supernatant was pipetted through a Millex $0.8-\mu \mathrm{m}$ filter into a preweighed glass vial and

87 then evaporated in a rotary evaporator at a temperature above that of hexane volatilization (69

$88{ }^{\circ} \mathrm{C}$ ). The containers were held overnight in a desiccator and then weighed to obtain the weight of

89 total greases and oils in the each sample; this value was divided by the weight of the whole

90 sample to obtain the concentration of total greases and oils.

Trace metals in sediments and larvae. Since trace metals are reported to cause deformities

92 in Chironomus larvae, ${ }^{8,10}$ we measured cadmium $(\mathrm{Cd})$, copper $(\mathrm{Cu})$, nickel $(\mathrm{Ni})$, thallium $(\mathrm{Tl})$

93 and zinc $(\mathrm{Zn})$ in surface sediments and in larvae collected in 2009 at station 1 in Parry Sound

94 Harbor and at the reference site. At each site, oxic sediment was collected by scraping a small

95 plastic spatula along the surface $(0-0.5 \mathrm{~cm})$ of intact Ekman grab $(15 \times 15 \times 23 \mathrm{~cm})$ samples and

96 then remaining sediment was sieved through a $0.5-\mathrm{mm}$ mesh-aperture net to concentrate $C$.

97 cucini larvae. In the laboratory, larvae were held in lake water for 4 days to allow them to

98 evacuate their gut contents. Fifteen well-depurated fourth-instar larvae were chosen from each

99 site and their head capsules were detached and preserved in alcohol for later examination for

100 deformities. Larval bodies and sediment samples were frozen at $-20{ }^{\circ} \mathrm{C}$ on pieces of pre-weighed

101 acid-washed Teflon sheeting held in acid-washed 1.5 mL Eppendorf tubes then freeze dried and

102 weighed. We then added Omni Trace nitric acid (100 $\mu \mathrm{L}$ per mg of sample) to each larval and

103 sediment sample as well as to samples of similar weight of certified reference materials (MESS-3

104 and PACS-2 for sediments and TORT-2 (lobster hepatopancreas) and bovine liver for biological 
105

106

107

108

109

samples). After five days at room temperature, hydrogen peroxide (60 $\mu \mathrm{L}$ of Trace Select Ultra per mg of samples) was added and samples were held for a further two days. Samples were topped up with ultra-pure water to a volume of $1 \mathrm{~mL}$ per $\mathrm{mg}$ of sample. Trace metals were measured by inductively coupled plasma - mass spectrometry; values of certified standards fell within the range of certified values. ${ }^{15}$

Collection and study of benthic invertebrates. In 2009, we collected 10 Ekman grab (15 x $15 \times 23 \mathrm{~cm}$ ) samples at each of stations 1 and 2 to measure the composition of the extant benthic community. Samples were sieved using a $0.5-\mathrm{mm}$ mesh-aperture net and preserved in $10 \%$ formalin to which we added a vital stain (Rose Bengal) to facilitate recovery of the invertebrates. We compared the population densities obtained with those from samples collected in 1973 (triplicate samples collected by Ekman grab in July). ${ }^{16}$

To retrieve subfossil chironomid head capsules, we cut a longitudinal half of core A into 5$\mathrm{mm}$ long slices that were sieved through a $100-\mu \mathrm{m}$ mesh-aperture sieve. Material retained was examined in a Bogorov dish under a microscope and head capsules found were mounted in Canada balsam on microscope slides.

In 2006 and 2009, we collected large numbers of Chironomus cucini larvae at station 1 in Parry Sound Harbor. In 2009, C. cucini larvae were also collected at station 2 in Parry Sound Harbor and at the reference site. Larvae were collected by Ekman grab, the contents of which were sieved using a $0.5-\mathrm{mm}$ mesh-aperture net and held in lake water at field temperatures for transport back to the laboratory where larvae were removed and preserved in $10 \%$ formalin. To measure deformities, the head capsule of each larva was removed and held in $10 \%$ potassium hydroxide $(\mathrm{KOH})$ for 30 minutes to digest soft tissues. The $\mathrm{KOH}$ was neutralized by holding the 
127 head capsule in concentrated acetic acid for 30 seconds and then it was transferred to $95 \%$

128 ethanol before being placed in Canada balsam on a microscope slide where it was cut laterally to 129 separate it into dorsal and ventral halves. The mandibles and antennae were removed and all 130 parts were covered with cover glasses and the slide was left to dry at room temperature for 131 several weeks. Several parts of the larval head capsule were found to be deformed including the 132 mentum, mandibles, pectin epipharyngis and the antennae as illustrated in Fig. S1.

133

134

135

136

137

138

139

140 profile (Fig. 1) is supported by the fact that peak ${ }^{137}$ Cs values occurred in the early 1960s (Fig.

141 2a) when inputs of fallout from atmospheric nuclear testing would have been at a maximum. ${ }^{13}$

142 Further support for the ${ }^{210} \mathrm{~Pb}$ dates comes from the relative concentrations of total $\mathrm{Pb}$ that

143 increase sharply through the 1920s, reach a maximum between the 1950s and the 1980s, and

144 then decline up to the present day (Fig. 2b). Such a pattern is coherent with the use of $\mathrm{Pb}$ as an

145 additive in gasoline. ${ }^{17}$

146 Concentrations of total greases and oils in sediment were below the detection limit at

147 sediment depths greater than $6.5 \mathrm{~cm}$ and less than $4 \mathrm{~cm}$, whereas between these depths 
148

149

concentrations ranged from 75 to $175 \mathrm{mg} / \mathrm{kg}$ (Fig. 2c). The large depth range of the oil suggests that there was some mixing of oil and previously deposited sediment at the time of the spill. Measurements of ${ }^{210} \mathrm{~Pb},{ }^{137} \mathrm{Cs}$, total $\mathrm{Pb}$ and total greases and oils were consistent in suggesting that $\approx 4.5 \mathrm{~cm}$ of sediment has accumulated at station 1 in Parry Sound Harbor since the 1950 oil spill. The relationship between sediment depth and ${ }^{210} \mathrm{~Pb}$ dates (Fig. 1) is consistent with a published value for mean sedimentation rates $(0.78 \mathrm{~mm}$ per year) in the near-shore waters of Georgian Bay ${ }^{18}$ since, at this rate, $\approx 4.5 \mathrm{~cm}$ of sediment would have accumulated between 1950 and 2009. The upper boundary of sediment rich in oil was also found at a depth of $\approx 4.5 \mathrm{~cm}$ (Fig. 2c), which suggests that oil from the 1950 spill has remained buried below this depth in the sediment of Parry Sound Harbor.

Trace metals in sediments and in Chironomus cucini. We measured the trace metals $\mathrm{Cd}$, $\mathrm{Cu}, \mathrm{Ni}, \mathrm{Tl}$ and $\mathrm{Zn}$ in sediments and larvae of C. cucini to determine if these contaminants could be responsible for deformities (as illustrated in Fig. S1). Concentrations of all trace metals, except copper, were significantly higher in sediments from Parry Sound Harbor (station 1, 2009) than at a reference site (Table 1), which is explained by the harbor's history as a centre of transport and industry for the region. ${ }^{3}$ In contrast, larvae from station 1 and the reference site showed no significant differences in their concentrations of most trace metals (Table 1; exceptionally, cadmium concentrations were marginally higher in larvae from Parry Sound Harbor). These results suggest that metals alone cannot explain the biological effects measured in Parry Sound Harbor. Indeed, much higher concentrations of $\mathrm{Cd}, \mathrm{Cu}, \mathrm{Ni}$ and $\mathrm{Zn}$ have been measured in Chironomus larvae from lakes in a mining area near Parry Sound (Sudbury, Ontario) and these larvae did not have elevated levels of deformities ( ${ }^{19}$; Proulx and Hare, 
170 unpublished). Likewise, laboratory experiments have shown that high incidences of deformities

171 in Chironomus larvae collected from contaminated lake sediments could not be explained by the

172 high lead content of the sediments. ${ }^{20}$ Although trace metals are reported to cause deformities in

173 Chironomus larvae in the laboratory, ${ }^{8,9,10,21}$ caution should be used when inferring cause and

174 effect relationships between high concentrations of trace metals in field sediments and

175 indicidences of larval deformities. Measurements of trace metal concentrations in burrowing

176 insects such as Chironomus would provide better estimates of metal bioavailability, ${ }^{22,23}$ which

177 could then be compared to the prevailing incidence of deformities. In conclusion, our data

178 suggest that the trace metals we measured are not the cause of deformities in C. cucini larvae,

179 however, we cannot rule out synergistic interactions between trace metals and oil in Parry Sound

180 Harbor.

Changes in benthic community composition over time. Benthic communities have been

182 severely impacted by oil spills in both marine ${ }^{24,25}$ and freshwater ${ }^{26}$ ecosystems. Their recovery is

183 reported to be more rapid in shallow, hard, substrates subject to strong currents than in deeper

184 regions characterized by soft sediments in both marine ${ }^{24,25}$ and freshwater ${ }^{26}$ systems. Thus

185 recovery of the benthic community in the cold, deep water, soft muds that we studied is likely to 186 relatively slow.

We compared densities of the numerically-dominant benthic taxa collected both 23 years

188 after the 1950 oil spill (in 1973) ${ }^{16}$ and 59 years after the spill (in 2009) to determine if they had

189 changed in the intervening decades. Note that the value of these comparisons is limited by the

190 small sample sizes in $1973(n=3)^{16}$ and the lack of data from intervening years. 
Densities of the amphipod crustacean Diporeia hoyi S. I. Smith, 1874, and the sphaeriid

192 mollusk Pisidium spp. were not significantly different in 1973 and 2009 (Fig. 3), which suggests

193 that populations of these taxa were well-established 23 years after the oil spill. Larvae of

194 Chironomus cucini were also present at station 1 in similar densities in 1973 and in 2009 (Fig.

195 3), which suggests that its population density, if the same at the time of the spill, had recovered

196 by 1973. However, the high incidence of deformities reported for this species in the mid-1970s, ${ }^{4}$

197 suggests continued contact with oily sediment at this time (as discussed below). Mean densities

198 of Tubificidae were lower in 1973 than in 2009 (Fig. 3), which suggests that populations of these

199 deep burrowing, sediment feeding, worms were affected by the spill but may not have recovered

200 by 1973.

We hypothesized that the recovery of a given benthic taxon in Parry Sound Harbor will

202 depend on the depth to which it burrows and feeds, with species living in near-surface sediments

203 recovering first as uncontaminated sediment gradually buries the spilled oil.

204 Given that the amphipod crustacean Diporeia hoyi (Fig. 3) feeds on freshly deposited

205 sediment and burrows little below the sediment surface, ${ }^{27,28}$ this species was likely one of the

206 first to recover from the oil spill. The sphaeriid mollusk Pisidium spp. (Fig. 3) should be one of

207 the next taxa to colonize station 1 since it lives within the first $5 \mathrm{~mm}$ of sediment where it is

208 reported to filter interstitial water to feed on micro-organisms. ${ }^{29}$ Judging from the similarity

209 between the densities of these two taxa in 1973 and 2009, we assume that if they were affected

210 by the 1950 spill they had recovered sometime prior to 1973 . By this date $\approx 2-2.5 \mathrm{~cm}$ of

211 uncontaminated sediment should have covered the oil (Fig. 1), which should be sufficient for

212 these shallow-burrowing taxa (Fig. 3). 
214 cucini were similar in 1973 and 2009 (Fig. 3), larvae of this species continued to contact oily

215 sediment in the mid-1970s. First, final-instar Chironomus larvae are reported to construct tubes

216 to mean depths of $\sim 4 \mathrm{~cm}$ in fine sediment, ${ }^{19}$ whereas only $\approx 2-2.5 \mathrm{~cm}$ of uncontaminated sediment

217 had been deposited by 1973 (Figs. 1 and 3). Second, at $\sim 2 \mathrm{~cm}$ in maximum length, vertically-

218 oriented larvae would have been close to the contaminated zone. Third, C. cucini larvae do not

219 feed in the water-column or on surface sediment, but on anoxic sediment below the surface oxic

220 zone. ${ }^{30}$ Fourth, the high incidence of deformities (Fig. S1) reported for this species two and a

221 half decades after the oil spill, ${ }^{4}$ indicates continued contact with oily sediment at this time (as

222 discussed below).

223 Tubificid oligochaetes (Fig. 3), and the tubificid genera reported to occur at station 1 in

224 Parry Sound Harbor (Ilyodrilus, Limnodrilus, Rhyacodrilus, and Tubifex), ${ }^{31}$ are thought to

225 construct vertical burrows in soft sediments and to consume deep sediment in a head-down

226 position. $^{32.33}$ The fact that the mean values of Tubificidae reported for 1973 were lower than

227 those we measured in 2009 (Fig. 3) suggests that populations of these deep burrowing and

228 feeding worms were affected by the spill but may not have fully recovered by 1973.

230 Parry Sound Harbor by studying changes in the chironomid community as revealed by head 231 capsules collected at various depths in a sediment core collected at station 1 . In the decade or so

232 following the oil spill (corresponding to a core depth of $\approx 4$ to $4.5 \mathrm{~cm}$ ), the numbers of the

233 numerically-dominant chironomid groups, that is, the Orthocladiinae (mainly

234 Heterotrissocladius), the Chironomini (mainly Chironomus, Dicrotendipes, Phaenopsectra, and 
235 Polypedilum), and the Tanytarsini (mainly Micropsectra and Tanytarsus) were reduced but

236 returned to their previous densities after this time (Fig. 4, upper panels). Exceptionally,

237 Diamesinae (all Protanypus) were absent prior to the oil spill but present thereafter (Fig. 4). The

238 low numbers of this taxon and the lack of ecological data on Protanypus make interpretation of

239 this pattern difficult. Larvae of Tanypodinae were in low and varying abundances over the time

240 interval studied (Fig. 4). Overall, the total numbers of subfossil Chironomidae show a minimum

241 near the estimated depth of the buried oil (Fig. 4), which suggests that the chironomid

242 community was decimated by the oil spill but had recovered within a decade or two after the

243 spill.

Of the 34 subfossil head capsules of C. cucini found at all depths in the sediment cores, only

2455 were deformed and, of these, 3 were found at the $4-4.5 \mathrm{~cm}$ depth interval, that is, near the time

246 of the oil spill.

Temporal changes in deformed Chironomus cucini. Examination of larval head capsules

248 showed that teeth on the mandibles, the mentum and the pecten epipharyngis were subject to loss

249 or deformation, as were the antennae (Fig. S1). Approximately two and a half decades after the

250 oil spill, 77\% of the C. cucini larvae collected at station 1 in Parry Sound Harbor (Fig. 5A; 85

251 larvae measured) had a deformed mentum, mandibles or both ${ }^{4}$ suggesting that contaminants were

252 still having an effect on this population. At that time, the comparable figure for a reference site

253 outside of Parry Sound Harbor was 2.5\% (Fig. 5A; 41 larvae measured). The results of other

254 studies also suggest that high incidences of deformities in Chironomus larvae are caused by

255 exposure to contaminants, ${ }^{34,35,36}$ whereas background levels of deformities are reported to be 
much lower. For example, in nearby Georgian Bay, only 5.3\% of Chironomus larvae were

257 reported to have a deformed mentum and $1.3 \%$ deformed mandibles. ${ }^{37}$

In 2009, the percentage of deformed individuals in Parry Sound Harbor was 12\% (of a total

259 of 146 larvae) at both stations 1 and 2 (Fig. 5A). We note that in 2006 a higher percentage of

260 deformed larvae was measured at station 1 ( $28.5 \%$ of 81 larvae), which suggests that the depth of

261 uncontaminated sediments covering the oil is spatially variable (the exact position of the

262 sampling site varied somewhat from year to year). The percentage of C. cucini larvae having a

263 deformed mentum or mandibles was very similar at the reference site (9\% of 129 larvae) and at

264 the two contaminated sites in Parry Sound Harbor (12\% of 103 in 2009; Fig. 5A), which suggests

265 that the majority of the Parry Sound Harbor population is no longer affected by contaminants. At

266 the reference site, the lower percentage of deformed individuals in the mid-1970s (2.5\% of 41

267 larvae $)^{4}$ compared to 2009 (9\%; Fig. 5A) is likely explained by the fact that the evaluator in 2009

268 (K. Bertrand) categorized a wider range of differences as being deformities that did the evaluator

269 of the earlier samples (L. Hare).

270 We found that deformities were not limited to the mentum and mandibles but that the

271 antennae and the pecten epipharyngis (part of the labium) could also be deformed (Fig. S1). In 3

272 of 4 cases (Fig. 5B), antennal deformities were at least as common as deformities of the mentum

273 and mandible. Individuals with deformities of the pecten epipharyngis were uncommon and were

274 recorded only in Parry Sound Harbor in 2009 (Fig. 5B). The fact that parts other than the

275 mentum and mandibles can be deformed suggests that the value of $77 \%$ deformed larvae in the

276 mid-1970s (Fig. 5A) would have been even higher if other head-capsule parts had been

277 examined. For a given part, deformities were further classified according to type (Figs. S1,6).

278 The only clear trend was that antennal deformities in larvae from Parry Sound Harbor mainly 
279 involved the loss of segments, whereas those from the reference site had multiple ring organs in 280 the basal segment (Figs. S1,6).

The deformities we observed do not appear to have hindered C. cucini larvae, since their

282

283

284

285

286

287

288

289

290

291

292

293

294

295

296

297

298

299

300

301

population density was similar in the mid-1970s and in 2009 and because deformed larvae were able to pupate successfully as determined by the fact that 5 of the 7 pupae that we collected had attached larval head capsules with deformed mouthparts.

A persistent population of deformed larvae suggests tolerance to oil. If so, C. cucini larvae could be used as sentinels to monitor recovery in the decades following an oil spill, since their tolerance allows them to persist in the presence of buried oil and yet their developmental sensitivity to the oil, as evidenced by deformities, allows for the quantification of contaminant exposure. Six decades after the oil spill, the low background level of deformities suggests that sufficient uncontaminated sediment has accumulated to allow C. cucini larvae to burrow and feed without contacting oil-contaminated sediment (Fig. 3).

Extrapolation from the Parry Sound Harbor oil spill. Our data suggest that biological effects on the benthos were extreme during the first decade or two following the oil spill, likely due to invertebrates contacting the oil either directly or indirectly through volatile components diffusing towards the sediment-water interface. If we assume that the burial of oily sediment allowed recovery of the benthic community, then recolonization likely proceeded according to the depths to which various taxa burrow, with surface-dwelling taxa reestablishing themselves first. At a given site, the greater the sedimentation rate the faster the benthic community will be able to completely recolonize sediments after an oil spill.

In the absence of light and at $4^{\circ} \mathrm{C}$, the oil at our study site is sufficiently stable that it continues to persist 6 decades after the oil spill. Although, it does not appear to be a current 
302 threat to most benthic invertebrates this could change in the future if, for example, sediments

303 were disturbed by dredging or by the arrival of a deep-burrowing invading species. In lakes

304 where bottom sediments are subject to disturbance by wind-induced currents, much longer time

305 frames could be required before oil is safely buried at depth. Such considerations will be

306 important in designing and evaluating the effectiveness of artificial lakes that are created to cover

307 oil-rich tailings, such as those being planned for use in the oil sands of northern Alberta. ${ }^{38}$ Since

308 our study is the first to address the long-term effects of oil in lakes, it will be useful for

309 evaluating the feasibility of such projects as well as the long-term recovery of freshwater benthic

310 communities impacted by oil.

311 Supporting Information.

312 The Supporting Information is available free of charge on the ACS Publications website at

313 DOI xxxx.

314 Figure S1. Deformed and normal structures of final instar Chironomus cucini larvae

315 collected from station 1 in Parry Sound Harbor.

316 ACKNOWLEDGMENTS.

317 Funding was provided by the National Sciences and Engineering Research Council of

318 Canada. Our thanks to Dominic Ponton for his help in the field, Pierre Francus for advice on

319 analyzing the sediment cores, Charles Gobeil for calculating ${ }^{210} \mathrm{~Pb}$ dates, Pamela Tagle-Nettle for

320 the TOC drawings, as well as Marthe Monique Gagnon and Isabelle Laroque and for their

321 comments on the masters thesis of Karen Bertrand. 


\section{REFERENCES}

1. Antonio, F. J., R. S. Mendes, and S. M. Thomaz. 2011. Identifying and modeling patterns of tetrapod vertebrate mortality rates in the Gulf of Mexico oil spill. Aquat. Toxicol. 105: 177179.

2. Owens, E. H., and J. Michel. 2002. Freshwater Oil Spills Special Issue. Spill Sci. Technol. Bull. 7: 113-114.

3. Ontario Visual Heritage Project. 2010. West Parry Sound. Rooted in Stone: reflections on West Parry Sound's past, Chapter 19: Industrial relicts. http://www.visualheritage.ca/parrysound.

4. Hare, L., and J. C. H. Carter. 1976. The distribution of Chironomus (ss)? cucini (salinarius group) larvae (Diptera: Chironomidae) in Parry Sound, Georgian Bay, with particular reference to structural deformities. Can. J. Zool. 54: 2129-2134.

5. Warwick, W. F. 1985. Morphological abnormalities in Chironomidae (Diptera) larvae as measures of toxic stress in freshwater ecosystems: indexing antennal deformities in Chironomus Meigen. Can. J. Fish. Aquat. Sci. 42: 1881-1914.

6. Hudson, L. A., and J. J. H. Ciborowski. 1996. Spatial and taxonomic variation in incidence of mouthpart deformities in midge larvae (Diptera: Chironomidae: Chironomini). Can. J. Fish. Aquat. Sci. 53: 297-304.

7. Janssens de Bisthoven, L., P. Nuyts, B. Goddeeris, and F. Ollevier. 1998. Sublethal parameters in morphologically deformed Chironomus larvae: clues to understanding their bioindicator value. Freshwat. Biol. 39: 179-191. 
8. Vermeulen, A. C., G. Liberloo, P. Dumont, F. Ollevier, and B. Goddeeris. 2000. Exposure of Chironomus riparius larvae (Diptera) to lead, mercury and b-sitosterol: effects on mouthpart deformation and moulting. Chemosphere 41: 1581-1591.

9. Martinez, E. A., L. Wold, B. C. Moore, J. Schaumloffel, and N. Dasgupta. 2006. Morphologic and growth responses in Chironomus tentans to arsenic exposure. Arch. Environ. Contam. Toxicol. 51: 529-536.

10. Di Veroli, A., E. Goretti, M. L. Paumen, M. H. S. Kraak, and W. Admiraal. 2012. Induction of mouthpart deformities in chironomid larvae exposed to contaminated sediments. Environ. Pollut. 166: 212-217.

11. Oliver, D. R., and M. E. Roussel. 1983. The genera of larval midges of Canada, Diptera: Chironomidae. Agriculture Canada, publication 1746.

12. Proulx, I., J. Martin, M. Carew, and L. Hare. 2013. Using various lines of evidence to identify Chironomus species (Diptera: Chironomidae) in eastern Canadian lakes. Zootaxa 3741: 401-458.

13. Appleby, P. G. 2001. Chronostratigraphic techniques in recent sediments, p. 171-203. In W. M. Last and J. P. Smol [eds.], Tracking environmental change using lake sediments. Kluwer Academic.

14. Couture, R.-M., C. Gobeil, and A. Tessier. 2008. Chronology of atmospheric deposition of arsenic inferred from reconstructed sedimentary records. Environ. Sci. Technol. 42: 65086513.

15. Rosabal, M., L. Hare, and P.G.C. Campbell. 2012. Subcellular metal partitioning in larvae of the insect Chaoborus collected along an environmental metal exposure gradient $(\mathrm{Cd}, \mathrm{Cu}, \mathrm{Ni}$ and Zn). Aquat. Toxicol. 120-121: 67-78. 
16. Hare, L. 1976. The macroscopic zoobenthos of Parry Sound, Georgian Bay. M.Sc. thesis. University of Waterloo.

17. Gallon, C., A. Tessier, C. Gobeil, and L. Beaudin. 2005. Sources and chronology of atmospheric and lead deposition to a Canadian Shield lake: Inferences from Pb isotopes and PAH profiles. Geochim. Cosmochim. Acta 69: 3199-3210.

18. Joshi, S. R. 1985. Recent sedimentation rates and ${ }^{210} \mathrm{~Pb}$ fluxes in Georgian Bay and Lake Huron. Sci. Total Environ. 41: 219-233.

19. Proulx, I., and L. Hare. 2014. Differences in feeding behavior among Chironomus species revealed by measurements of sulphur stable isotopes and cadmium in larvae. Freshwat. Biol 59: 73-86.

20. Wise, R. R., C. A. Pierstorff, S. L. Nelson, R. M Bursek, J. L. Plude, M. McNello, and J. Hein. 2001. Morphological deformities in Chironomus (Chironomidae: Diptera) larvae as indicators of pollution in Lake Winnebago, Wisconsin. J. Great Lakes Res. 27: 503-509.

21. Janssens de Bisthoven, L., J. Postma, A. Vermeulen, G. Goemans, and F. Ollevier. 2001. Morphological deformities in Chironomus riparius Meigen larvae after exposure to cadmium over several generations. Water, Air, and Soil Pollution 129: 167-179.

22. Michaud, A.L., L. Hare, and P.G.C. Campbell. 2005. Exchange rates of cadmium between a burrowing mayfly and its surroundings in nature. Limnol. Oceanogr. 50: 1707-1717.

23. Martin, S., I. Proulx, and L. Hare. 2008. Explaining metal concentrations in sympatric Chironomus species. Limnol. Oceanogr. 53: 411-419.

24. Lee, L. H., and H. J. Lin. 2013. Effects of an oil spill on benthic community production and respiration in subtropical intertidal sandflats. Mar. Pollut. Bull. 73: 291-299. 
25. Montagna, P. A., J. G. Baguley, C. Cooksey, I. Hartwell, L. J. Hyde, J. L. Hyland, R. D. Kalke, L. M. Kracker, M. Reuscher, and A. C. E. Rhodes. 2013. Deep-sea benthic footprint of the deepwater horizon blowout. PLOS ONE 8: e70540.

26. Poulton, B. C., S. E. Finger, and S. A. Humphrey. 1997. Effects of a crude oil spill on the benthic invertebrate community in the Gasconade River, Missouri. Arch. Environ. Contam. Toxicol. 33: 268-276.

27. Marzolf, G. R. 1965. Substrate relations of the burrowing amphipod Pontoporeia affinis in Lake Michigan. Ecol. 46: 580-592.

28. Nalepa, T. F., D. L. Fanslow, and G. A. Lang. 2009. Transformation of the offshore benthic community in Lake Michigan: recent shift from the native amphipod Diporeia spp. to the invasive mussel Dreissena rostriformis bugensis. Freshwat. Biol. 54: 466-479.

29. Holopainen, I. J., and G. R. Lopez. 1989. Functional anatomy and histology of the digestive tract of fingernail clams (Sphaeriidae, Bivalvia). Ann. Zool. Fennici 26: 61-72.

30. Charbonneau, P., and L. Hare. 1998. Burrowing behavior and biogenic structures of muddwelling insects. J. N. Amer. Benthol. Soc. 17: 239-249.

31. Hare, L., and J. C. H. Carter. 1977. The Oligochaeta, Polychaeta and Nemertea of Parry Sound, Georgian Bay. J. Great Lakes Res. 3: 184-190.

32. Davis, R. B. 1974. Tubificids alter profiles of redox potential and $\mathrm{pH}$ in profundal lake sediment. Limnol. Oceanogr. 19: 342-346.

33. Leynen, M., T. Van den Berckt, J. M. Aerts, B. Castelein, D. Berckmans, and F. Ollevier. 1999. The use of Tubificidae in a biological early warning system. Environ. Poll. 105: 151154. 
34. Cushman, R. M. 1984. Chironomid deformities as indicators of pollution from a synthetic, coal-derived oil. Freshwat. Biol. 14: 179-182.

35. Cortelezzi, A., A. C. Paggi, M. Rodrìguez, and A. R. Capìtulo. 2011. Taxonomic and nontaxonomic responses to ecological changes in an urban lowland stream through the use of Chironomidae (Diptera) larvae. Sci. Total Environ. 409: 1344-1350.

36. Lenat, D. R. 1993. Using mentum deformities of Chironomus larvae to evaluate the effects of toxicity and organic loading in streams. J. N. Amer. Benthol. Soc. 12: 265-269.

37. Burt, J., J. J. H. Ciborowski, and T. B. Reynoldson. 2003. Baseline incidence of mouthpart deformities in Chironomidae (Diptera) from the Laurentian Great Lakes, Canada. J. Great Lakes Res. 29: 172-180.

38. Vanderklippe, N. 2012. Ambitious plans for oil sands would create lakes from waste. Globe and Mail. 3 October. http://www.theglobeandmail.com/news/national/ambitious-plans-foroil-sands-would-create-lakes-from-waste/article4583817/ 
Table 1. Mean $( \pm 95 \% \mathrm{CI})$ concentrations (nmol/g dry weight) of the trace metals $\mathrm{Cd}, \mathrm{Cu}, \mathrm{Ni}, \mathrm{Tl}$ and $\mathrm{Zn}$ in sediments and in larvae of Chironomus cucini collected in 2009 at a reference site in Parry Sound and in Parry Sound Harbor (station 1). Overlap of confidence intervals indicates no significant difference between means.

\begin{tabular}{lccccc}
\hline \multicolumn{1}{c}{ Metal: } & $\mathrm{Cd}$ & $\mathrm{Cu}$ & $\mathrm{Ni}$ & $\mathrm{Tl}$ & $\mathrm{Zn}$ \\
Medium / station & $(\mathrm{nmol} / \mathrm{g})$ & $(\mathrm{nmol} / \mathrm{g})$ & $(\mathrm{nmol} / \mathrm{g})$ & $(\mathrm{nmol} / \mathrm{g})$ & $(\mathrm{nmol} / \mathrm{g})$ \\
\hline Sediment - reference & $17 \pm 2$ & $578 \pm 294$ & $435 \pm 94$ & $0.8 \pm 0.03$ & $2987 \pm 703$ \\
Sediment - Parry Sound Harbor & $37 \pm 3$ & $884 \pm 79$ & $703 \pm 99$ & $1.7 \pm 0.03$ & $8883 \pm 1014$ \\
C. cucini - reference & $23 \pm 6$ & $330 \pm 97$ & $15 \pm 7$ & $0.08 \pm 0.04$ & $842 \pm 272$ \\
C. cucini - Parry Sound Harbor & $63 \pm 29$ & $217 \pm 127$ & $26 \pm 5$ & $0.04 \pm 0.02$ & $1191 \pm 816$ \\
\hline
\end{tabular}




\section{FIGURE CAPTIONS}

Figure 1. Changes in sediment age with depth in core A collected at station 1 in 2009 from Parry Sound Harbor, as determined by ${ }^{210} \mathrm{~Pb}$ measurements. Error bars are standard deviations (SD).

Figure 2. Depth profiles of variables in cores collected at station 1 in 2009 from Parry Sound Harbor: (a) ${ }^{137}$ Cs activity ( $\pm \mathrm{SD}$, core A); (b) total $\mathrm{Pb}$ (core A); (c) total greases and oils (core B). Dates are derived from ${ }^{210} \mathrm{~Pb}$ geochronology.

Figure 3. Schematic representation of presumed burrowing and feeding depths of the four numerically-dominant benthic invertebrates at station 1 in Parry Sound Harbor as related to the depths of the 1950 oil spill and to the sediment-water interface in 1973 and 2009 as well as their mean densities ( $\pm 95 \%$ confidence interval) in these two years. Also pictured is the middle tooth of the mentum of deformed (1973) and normal (2009) Chironomus cucini larvae.

Figure 4. Numbers of chironomid head capsules in $0.5-\mathrm{cm}$ slices of core A collected from station 1 in Parry Sound Harbor. The 1950 oil spill corresponds to a sediment depth of $\approx 4.5 \mathrm{~cm}$.

Figure 5. Deformities in Chironomus cucini from a reference station and two stations in Parry Sound Harbor. Larvae were collected in either the 1970s (1973 and 1976 ${ }^{4}$ ) or 2009 (this study). a: percentage of larvae having either a deformed mentum or deformed mandibles (numbers examined given above bars). b: percentage of deformed larvae exhibiting various types of deformities (totals can exceed 100\%, since individuals can have more than one deformed part).

Figure 6. Percentages of various types of deformities observed in the various parts of deformed Chironomus cucini larvae collected at two stations in Parry Sound Harbor (1 and 2) and at a reference station outside of Parry Sound Harbor. Larvae were collected in 2009 from all stations and in 2006 from station 1. 


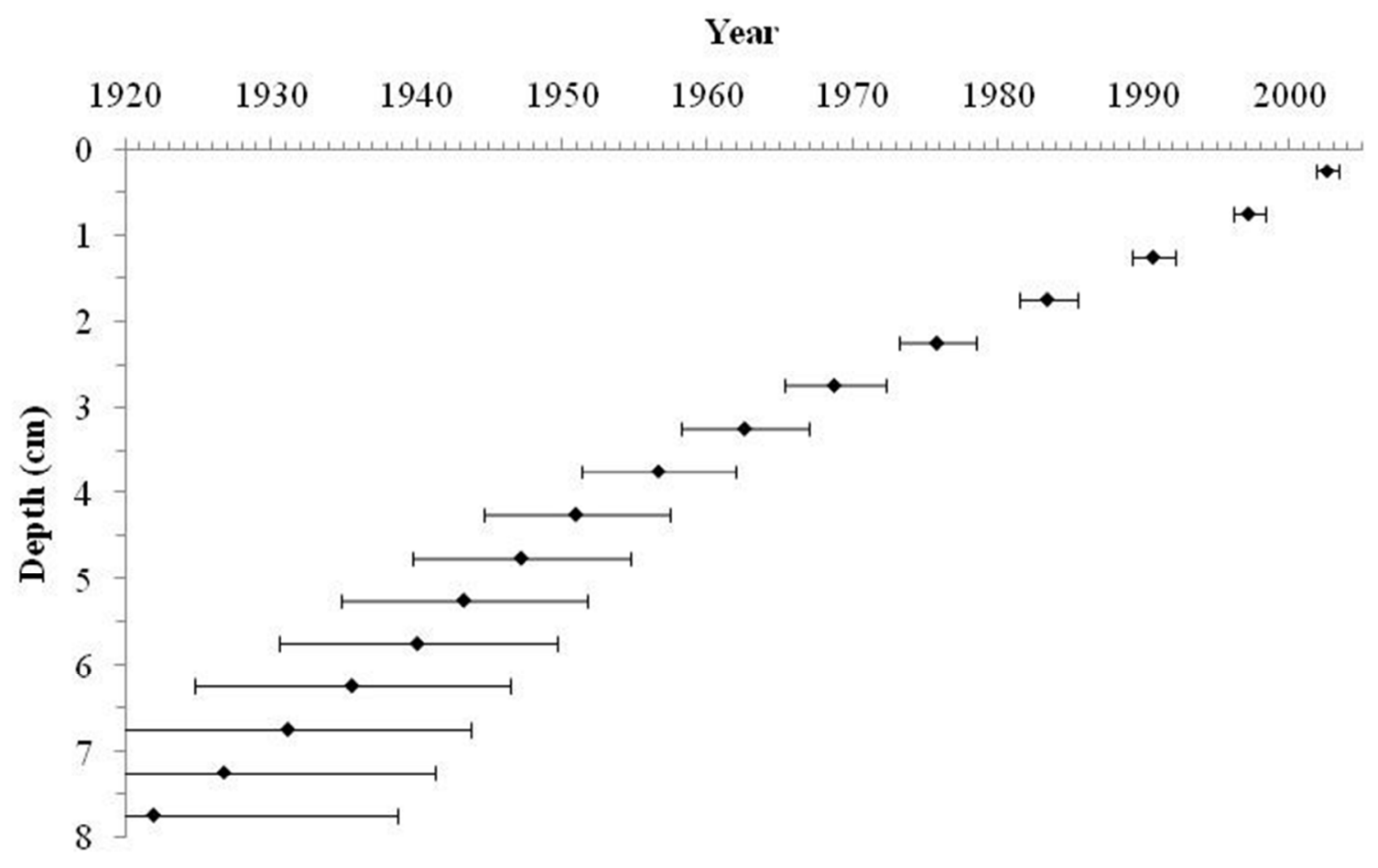

Figure 1. 


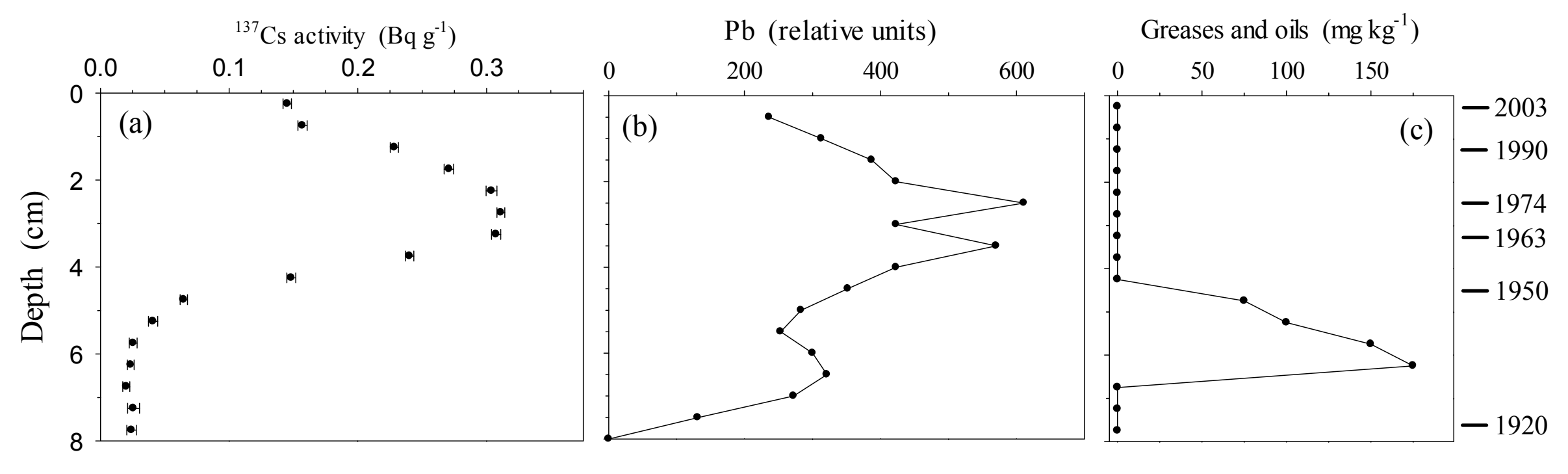

Figure 2. 


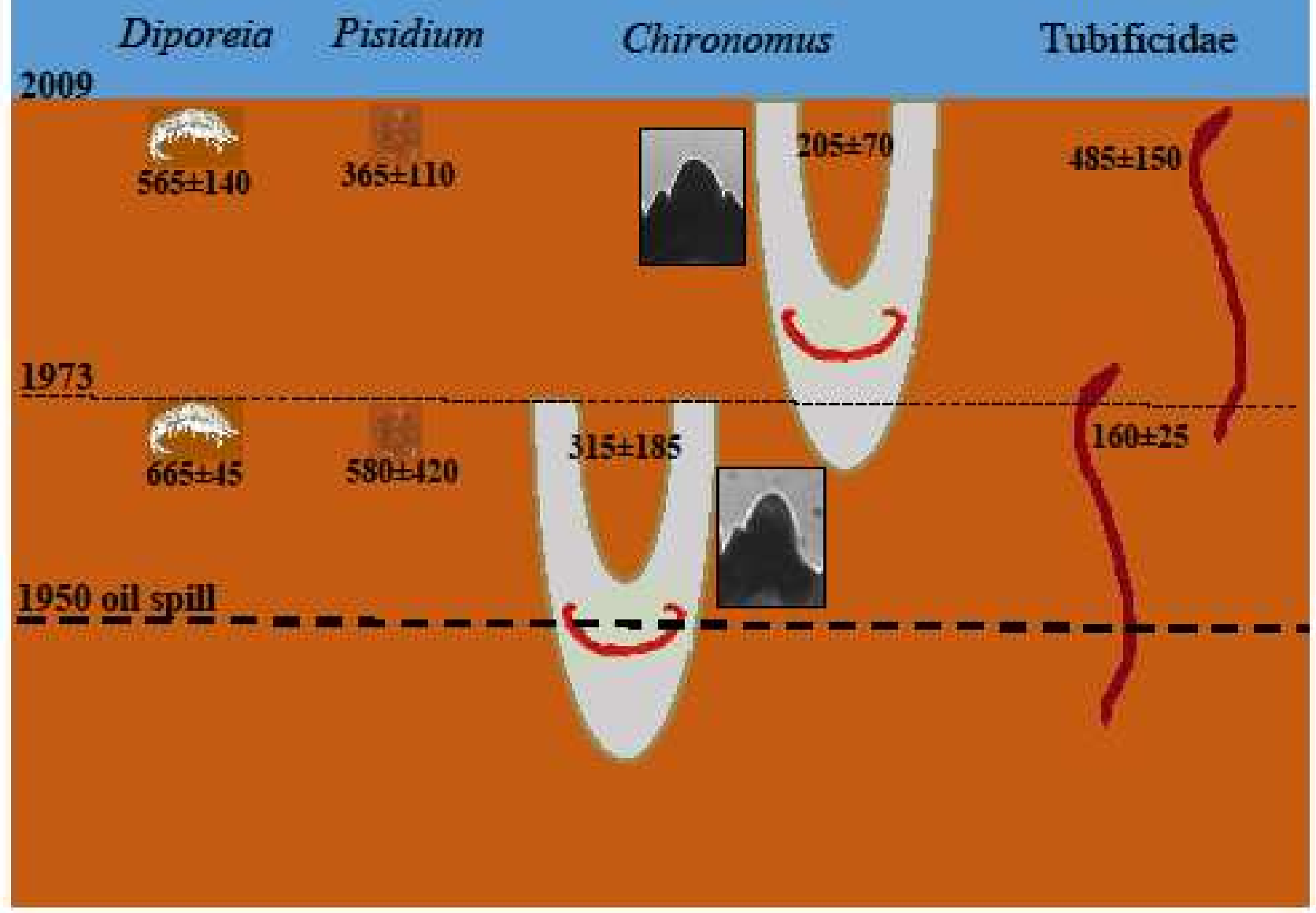

Figure 3. 

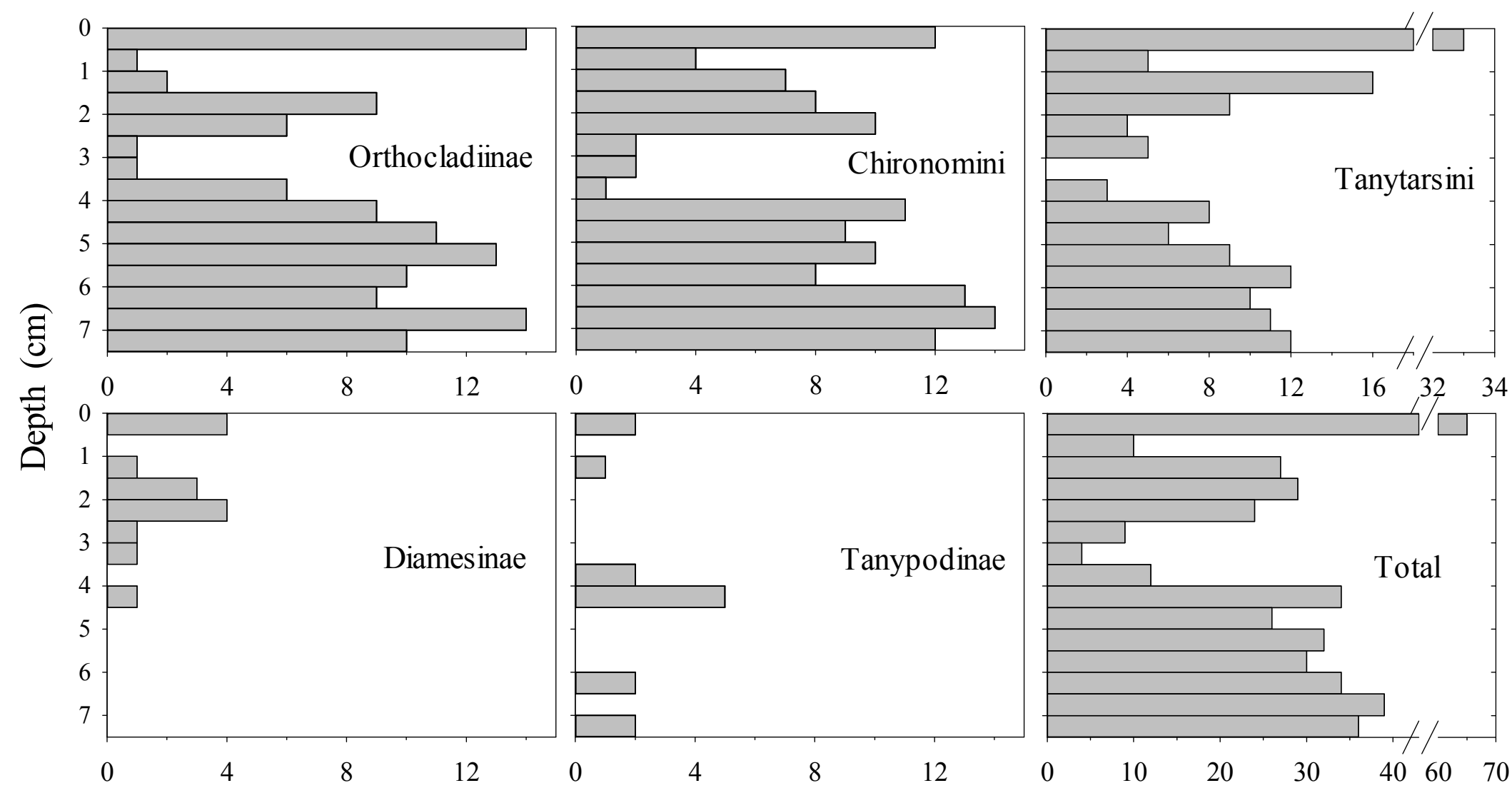

Numbers of subfossil chironomid head capsules per depth interval

Figure 4. 

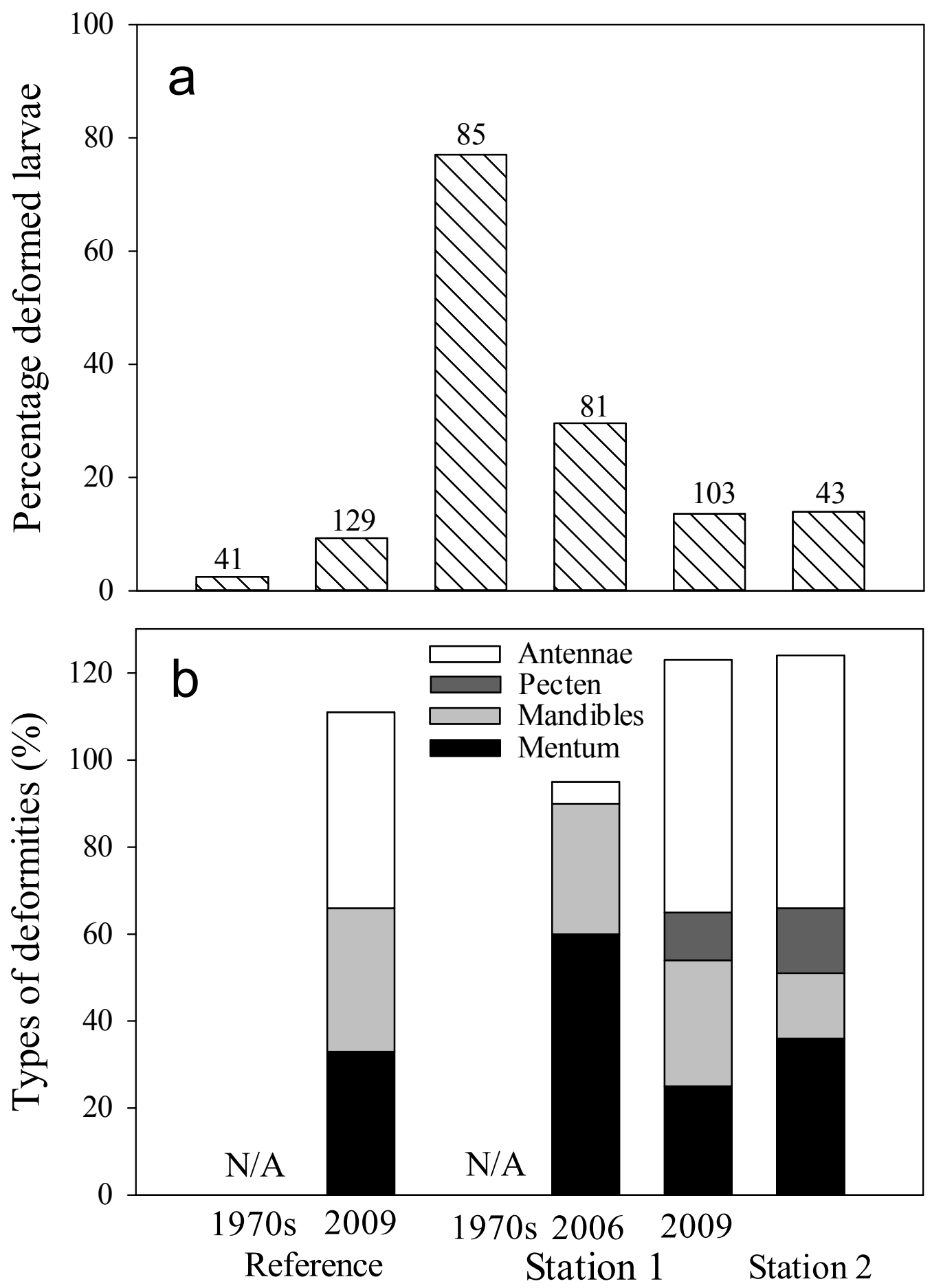

Figure 5. 

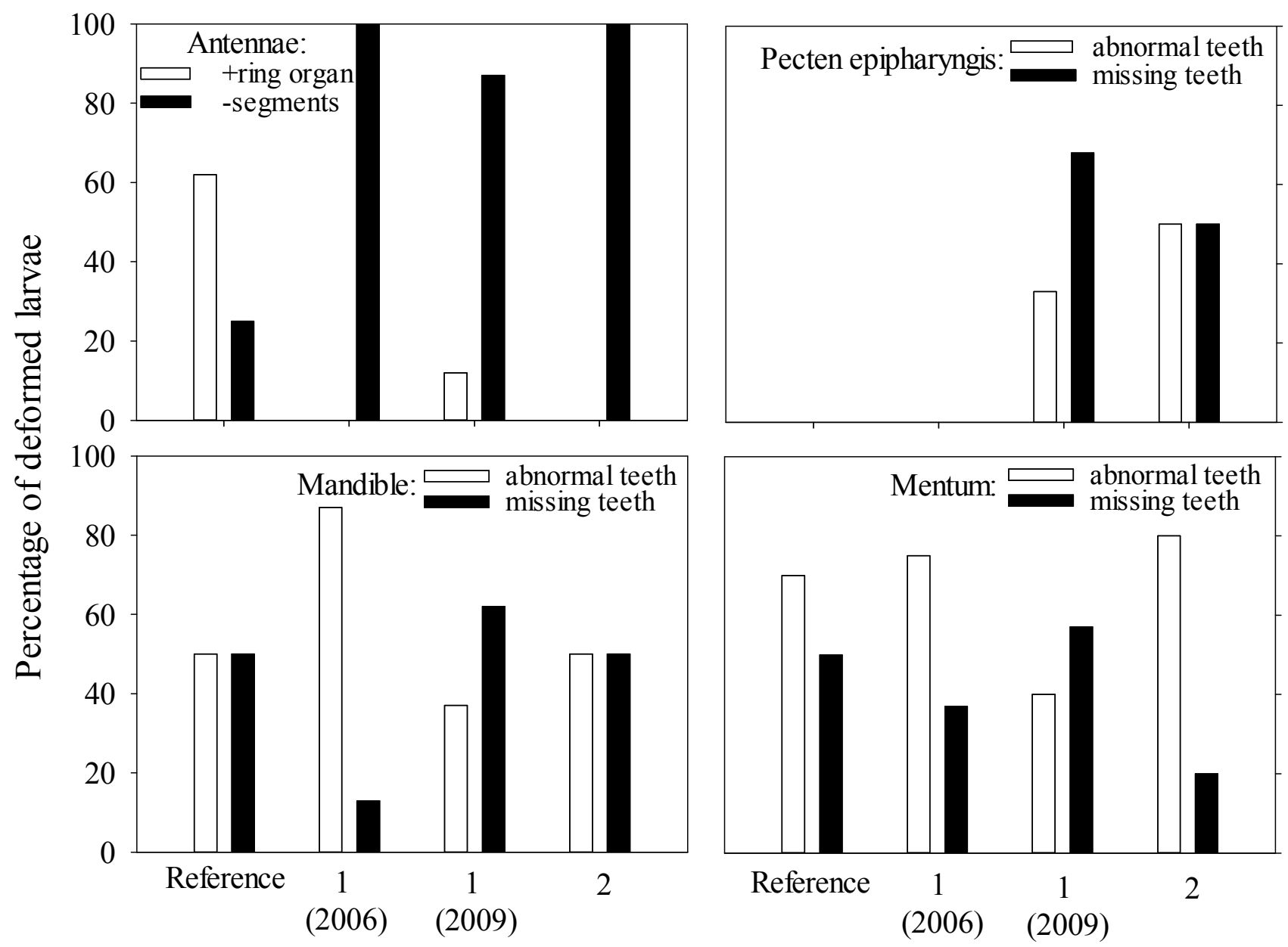

Figure 6. 